\title{
Pensando a fotografia na pesquisa qualitativa em psicologia
}

\section{Thinking in a photograph qualitative research in psychology}

\section{J oana Sanches J usto*}

Doutoranda do programa de pós-graduação em Psicologia da Universidade Estadual Paulista - UNESP, Assis, SP, Brasil

\section{Mário Sérgio Vasconcelos**}

Docente da graduação e pós-graduação, Professor Livre-docente em Psicologia do Desenvolvimento pela Universidade Estadual Paulista UNESP, Assis, SP, Brasil

\begin{abstract}
RESUMO
Considerando que a fotografia está cada vez mais presente na comunicação e no cotidiano, entendemos que cabe também explorar suas possibilidades como instrumento de pesquisa. Nesse sentido, fizemos um levantamento dos estudos em que se utiliza a fotografia na metodologia de investigação e analisamos o alcance e limitações de seu uso. O exame das poucas pesquisas que se valeram da fotografia demonstrou que o recurso fotográfico é ainda pouco explorado pela Psicologia como um recurso eliciador da subjetividade. Concluímos que explorar a utilização deste recurso pode ser bastante útil e contribuir significativamente para a investigação científica no campo da Psicologia.
\end{abstract}

Palavras-chave: Pesquisa qualitativa, Psicologia, Fotografia.

\begin{abstract}
Whereas the picture is increasingly present in the communication and daily life, we believe in also exploring its potential as a tool for research. Accordingly, we did a survey of studies in which the research methodology it is intermediate by photograph and analyze the scope and limitations of its use. The examination of the few studies that use the photography demonstrates that this resource is still little explored by psychology as means of access to the subjectivity. We conclude that explore the use of this feature can be useful and a significant contribution to scientific research in the field of psychology.
\end{abstract}

Keywords: Photograph, Qualitative Research, Psychology. 


\section{I ntrodução}

Atualmente nos parece óbvio pensar que a subjetividade, desvendada através da linguagem, nos permite realizar pesquisas em Psicologia. Cabe lembrar que este campo de conhecimento nem sempre teve, em suas pesquisas, a preocupação de atingir o intrínseco, 0 subjetivo, o que é variável entre os seres humanos. Antes de se voltar à subjetividade, a Psicologia serviu à normalização, à busca de padrões e da universalidade das características humanas. O interessante do retorno aos primórdios da pesquisa em Psicologia é perceber que já neste momento a fotografia estava presente.

Segundo Neiva-Silva e Koller (2002), o primeiro artigo publicado, por Donaldson, que se utiliza da fotografia na pesquisa psicológica data do final do século XIX, época do desenvolvimento das primeiras formas de captura de imagens via câmaras escuras. De acordo com estes autores, concomitantemente ao surgimento da fotografia a Psicologia é reconhecida como ciência.

Esta primeira publicação não dava lugar de destaque à fotografia, usando-a apenas como instrumento de registro, tomando-a como mais um dado em meio a tantos outros e tinha o propósito de relacionar a anatomia cerebral com a inteligência. Os resultados consideravam tanto notas biográficas do paciente estudado quanto fotografias da autópsia, peso e volume encefálico.

Muito tempo e muitas pesquisas se passaram antes de a fotografia ganhar um papel além do registro de dados coletados. No início do século $X X$, ainda mais próxima da pesquisa quantitativa, a fotografia serviu para a seleção de pessoas capacitadas a trabalhar na reconstrução pós-guerra. Tal pesquisa (ANDERSON, 1921 apud NEIVA-SILVA; KOLLER, 2002) tentava criar um critério, comparando traços faciais com QI, que rapidamente indicassem quais pessoas se encaixariam em categorias relacionadas à inteligência superior ou inferior. Como conclusão deste estudo, tal método não foi considerado confiável uma vez que não foi possível correlacionar significativamente as imagens com o coeficiente de inteligência.

Outra pesquisa da época, realizada por Pintner em 1918 (apud NEIVA-SILVA; KOLLER, 2002), procurava relacionar traços físicos com a inteligência, desta vez, com crianças. Um corpo de juízes composto por profissionais de diversas áreas deveria organizar as fotos em uma seqüência que indicasse qual criança teria maior ou menor nível de inteligência. Também neste caso os resultados foram inconclusivos (NEIVA-SILVA; KOLLER, 2002).

Ainda que hoje nos pareça absurdo, diante de tantas questões sobre preconceito racial, físico e tantos outros, "julgar o livro pela capa", ou seja, a pessoa pela aparência, os autores acima citados nos fazem perceber o quanto os resultados inconclusivos das fotografias neste tipo de teste impulsionaram a produção de testes de personalidade e inteligência mais válidos, além de não mais legitimar, na escola, o 
poder do professor julgar a inteligência ou empenho do aluno de acordo com sua aparência. É claro que a insistência em buscar padrões físicos para a inteligência, o bom comportamento ou a classe social ainda persiste, mas esta não é uma discussão pertinente ao tema deste artigo.

As primeiras formas de incluir a fotografia como recurso para a pesquisa em Psicologia se relacionaram, portanto, principalmente à coleta de dados concretos e padrões físicos. Aos poucos, o cenário foi se modificando e as possibilidades tanto da pesquisa quanto dos recursos nela empregados se ampliaram. A fotografia foi sendo utilizada em substituição à descrição de situações em questionários, já que ilustrava a situação de forma mais concreta e palpável.

A partir deste segundo passo na introdução da fotografia como recurso na Psicologia, quando o que está envolvido não é apenas a coleta de dados, mas também a subjetividade, abrem-se as portas para a pesquisa qualitativa, para a interação entre o pesquisador e o participante que fornece os dados a partir do seu ponto de vista. Neiva-Silva e Koller (2002), inclusive, citam um caso em que, na clínica psicológica, ao pedir que a paciente trouxesse algumas de suas fotografias para a sessão, o terapeuta conseguiu que sua relação com o paciente fosse significativamente modificada.

Inserir a fotografia na pesquisa qualitativa é um processo muito diferente dos descritos até aqui uma vez que, em primeiro lugar, a neutralidade do pesquisador é deposta e, em segundo, busca-se dar vazão à subjetividade dos participantes. Fazer uma pesquisa qualitativa é lidar com dados inexatos, flexíveis e mutáveis que não podem ser generalizados, como se pretendia com as fotografias relacionadas aos testes de inteligência.

\section{A pesquisa qualitativa}

Antes mesmo de pensarmos na possibilidade de a fotografia ser utilizada como um recurso na Psicologia, os estudos neste campo de conhecimento já implicavam em muitas discussões, principalmente sobre o caráter quantitativo e o qualitativo da pesquisa. Atualmente a disputa entre estes dois métodos já se tornaram obsoletas. Fala-se não em uma melhor forma, mais ou menos científica, de pesquisar, mas sim na postura do pesquisador frente ao fenômeno estudado. Esta, sim, é a grande característica que diferencia uma pesquisa quantitativa de uma qualitativa.

Se, por um lado, a pesquisa quantitativa ampara-se principalmente no positivismo e preocupa-se com dados estatísticos, medição de unidades e categorias homogêneas, a pesquisa qualitativa volta-se ao estudo de fenômenos igualmente complexos, mas compreendendo-os de forma que o pesquisador tenha uma postura de menor neutralidade diante do seu objeto de estudo. Uma pesquisa, 
qualitativa ou quantitativa, pode valer-se de categorizações e também do estudo de qualidades. Em pesquisas quantitativas podem-se usar testes fatoriais e, em qualitativas, projetivos, por exemplo.

Nenhum fenômeno tomado como problema da pesquisa é objeto exclusivo de um método específico, mesmo porque não é necessário limitar as possibilidades de seu estudo e compreensão. Ainda assim, as discussões deste artigo desenvolvem-se em torno das características qualitativas da pesquisa científica e do ponto de vista do pesquisador perpassando seu estudo.

De acordo com Pinto (2004), a Psicologia, como ciência humana complexa, é influenciada por fatores histórico-culturais, individuais e coletivos, que afetam o ponto de vista do pesquisador e sua construção da pesquisa. Existe uma interação, no decorrer da pesquisa, entre o objeto de estudo e o pesquisador.

\begin{abstract}
A epistemologia específica dessa maneira de investigar parte do princípio que a própria investigação interfere no objeto a ser investigado e, por isso, não há neutralidade possível. A pesquisa está sempre associada à realidade e à subjetividade do pesquisador. Portanto, há influências diretas e indiretas, conscientes e inconscientes do pesquisador na própria ciência que produz, tendo em vista que a sua produção sofre interferências de sua história e de seu funcionamento psicológico (PINTO, 2004, p. 09).
\end{abstract}

Considerar tal interação é também admitir que pesquisas qualitativas na área da Psicologia não podem ser completamente neutras: não existe pretensão de chegar a conclusões fechadas ou comprovar empiricamente deduções teóricas, uma vez que até mesmo as hipóteses podem surgir e se modificar ao longo da pesquisa. Segundo Rey (2001), o pesquisador deve considerar o caráter interativo e subjetivo do objeto de estudo da Psicologia, uma vez que, sem a implicação subjetiva dos sujeitos da pesquisa os dados estariam comprometidos, pois perderiam significação, elemento necessário para a construção do conhecimento na pesquisa qualitativa.

O conhecimento qualitativo é uma produção de construções e interpretações, ou seja, não é apenas a soma de experiências, mas também a necessidade de atribuir-lhes sentidos. Na tentativa de compreender os dados concretos obtidos no processo investigativo, surge a interpretação: um processo constante no qual o investigador constrói indicadores que não fariam sentido se tomados isoladamente, como meras constatações empíricas.

A interpretação é um processo diferenciado que dá sentido a diferentes manifestações concretas do estudado e as convertem em momentos particulares do processo mais geral orientado à construção teórica do sujeito, seja em sua 
condição de sujeito social, como a família, a comunidade, a escola etc., ou de sujeito individual (REY, 2001, p.38).

A interpretação se realiza através da unicidade e complexidade do objeto estudado onde a teoria está presente a todo o momento, mas não como hipóteses apriorísticas capazes de explicar tudo o que 0 indivíduo ou grupo estudado expressa. A interpretação dá direções ao pesquisador durante o processo investigativo, principalmente quando este vai a campo e entra em contato com situações que não podem ser calculadas previamente por meio de teorizações. Até mesmo as situações imprevistas ou informais podem ser contextualizadas na pesquisa, tornando-se relevantes para a construção do conhecimento. Não existem, portanto, regras pré-definidas para que se realize uma pesquisa qualitativa uma vez que, independentemente do instrumento utilizado (questionários, entrevistas, sessões de grupo), a construção resultante da interação entre o pesquisador e seu objeto de estudo é particular. A fala de um sujeito, por exemplo, pode disparar sentidos apenas em um indivíduo e não no restante de um grupo.

Esta singularidade conferida ao sujeito permite que este seja visto de uma forma diferenciada, detentor de uma subjetividade que pode ser expressa, que atua nas suas produções e no seu modo de vida, que faz deste sujeito um ser único. A subjetividade, portanto, é outro elemento que deve ser observado quando se trata de uma pesquisa qualitativa. Entretanto, o que é subjetividade? O que exatamente deve ser observado?

\section{Lidando com o inexato: subjetividade e fotografia}

Segundo Rey (2001) a subjetividade são os sentidos e as significações produzidas em um âmbito cultural ainda que seja assimilada particularmente por cada membro da sociedade. Há, portanto, uma subjetividade social e uma individual que se interrelacionam. O sujeito, possuindo sua história pessoal e vivendo em sociedade, participa dos sistemas subjetivos que caracterizam a subjetividade social produzindo dentro dela novos sentidos. Em contrapartida, a sociedade retorna ao indivíduo novos sentidos que estarão implicados no seu desenvolvimento subjetivo.

Através da subjetividade é possível alcançar aspectos psíquicos inerentes ao homem, objeto de estudo da Psicologia, tais como sua história de vida, personalidade, estrutura psíquica, patologias etc., pois todos estes conteúdos encontram-se subjetivados e organizados psiquicamente no sujeito. Entretanto, para que tais conteúdos subjetivos possam ser estudados é necessário fazer uso de formas de expressão do sujeito, como a comunicação, que permitem emergir tais aspectos ainda que implicitamente. 
A linguagem, geralmente a fala, é um meio de comunicação muito usado para acessar a subjetividade. A comunicação, por sua vez, é o veículo pelo qual o homem pode se relacionar com o mundo, transmitir-se. A comunicação é, portanto, um processo intensamente presente nas relações humanas que possibilita a expressão de intenções e a mobilização de conteúdos pessoais organizados sob a forma de mensagens.

Para que a comunicação de fato ocorra, tais mensagens devem ser transmitidas e, para isso, devem conter códigos que possam ser compreendidos por quem as recebe. A interação comunicativa entre as pessoas pode, então, ir muito além de palavras e verbalizações, uma vez que envolve inúmeros fatores (como tom de voz, olhares, postura e contexto) que, em conjunto, constroem o seu significado (BERLO, 1963).

A humanidade, nos primórdios de sua existência, criou a linguagem a fim de organizar sua proteção e subsistência em grupo. A partir desta necessidade o homem criou rituais, mitos e pinturas nas paredes visando transmitir mensagens e construir um meio de comunicação que pudesse ser decodificado amplamente pela sua comunidade. Neste sentido, Parreira (2005) comenta que as formas de expressão desenvolvidas pelo homem envolvem também sua capacidade criativa e imaginativa, o que pode ser claramente observado na dança, no canto, na pintura e na escrita.

Com o passar do tempo, as primeiras imagens, símbolos pintados nas cavernas, foram subjetivamente sendo apropriadas pelo homem e rapidamente decodificadas, tornando-se significados. Neste processo comunicativo o sentido e o conteúdo não se separam da mensagem, mas fundem-se e criam um universo simbólico, tal como a representação mental e o significado da palavra "casa" parecem óbvios e inseparáveis.

Esta construção pode ser observada no desenvolvimento da linguagem na criança. No princípio, esta se comunica com gestos, balbucios, choros e cabe à mãe reconhecer tais expressões, dar-lhes sentido e prover $o$ bebê na medida em que surgem suas necessidades. Entretanto, esta forma difusa da comunicação faz com que a mãe muitas vezes interprete erroneamente o pedido do bebê e, por isso, esta forma de expressão precisa ser aprimorada pela criança, engajando-a no processo simbólico (PARREIRA, 2005).

É preciso salientar que, apesar desta característica individual do processo simbólico, ele não ocorre sozinho e sim dentro de um contexto social. Quando uma comunidade inteira compartilha o mesmo significado para um objeto, sua representação comum transforma-se em signo e integra-se ao repertório comunicativo deste grupo. Portanto, o signo e as percepções do homem são produzidos ou "fabricados" socialmente, isto é, possuem uma forte inscrição num 
dado tempo e lugar marcado pelas relações entre os homens (BLIKSTEIN, 1983).

A comunicação, enquanto jogo ou trama de veiculação de signos, enunciados e discursos, não é apenas um recurso técnico para a veiculação de intenções e informação, mas é um importante instrumento de produção ou sustentação de relações sociais. Ela veicula ideologias, formas de ver e entender o mundo conforme hegemonias criadas numa dada organização social. Comunicar é dizer não apenas do mundo, mas de si mesmo. É fazer uso dos elementos disponíveis e transmitir uma mensagem, uma intenção, emoção e demais produções do sujeito.

De acordo com Berlo (1963), tudo aquilo a que pode ser atribuída uma significação pode ser usado na comunicação, fazendo com que esta tenha um amplo campo de possibilidades. $O$ vento, as temperaturas, os aromas, o toque nas pessoas e objetos são informações que recebemos por todos os nossos sentidos. Tudo isso fornece pistas sobre o local em que estamos, indica-nos algo e provoca impressões que podem desencadear 0 processo comunicativo.

É preciso, então, repensar a comunicação estritamente como escrita e fala, pois suas possibilidades atingem todos os órgãos dos sentidos. As formas de expressão que cada vez mais ganham espaço atualmente estão relacionadas à visualidade. São anúncios gritados nas portas das lojas, outdoors, banners, painéis eletrônicos, rótulos e embalagens, exposições de arte, espetáculos de dança, circo e teatro, dentre outros.

O código visual amplia e modifica a forma de ver o mundo e de selecionar o que vale a pena olhar. Ao nosso redor, imagens e mais imagens que saltam aos olhos, e se transformam em ícones capazes de representar um indivíduo, seja através de documentos pessoais que têm sua veracidade atestada pela imagem fotográfica, seja o cartão de visita com um slogan personalizado.

O grande avanço nas tecnologias de comunicação visual criou uma nova realidade: o mundo-imagem, o aumento das possibilidades de virtualização da realidade, de materialização da subjetividade e dos registros semióticos em formas que podem permanecer no tempo além de quem as produz. Esta nova linguagem imagética abre espaço para uma relação idiossincrática entre o homem e as coisas: a mediação imagética entre ele e sua realidade.

A fotografia produz um tipo de imagem que serve muito bem como mediadora da realidade: uma forma de capturar os objetos e tornar desnecessária a sua presença. Por ela, é possível conhecer lugares ou pessoas sem sair do lugar. Aos olhos do observador torna-se o que mostra seu recorte: uma senhora sentada na varanda é a minha avó e não apenas uma imagem dela. Da mesma forma, quando uma 
pessoa mostra suas fotos afirma sem titubear: "esta sou eu", como se fosse a própria pessoa.

Wolff (2005) corrobora que existe certa maleabilidade entre os limites do objeto e seu retrato e, embora tomemos a fotografia como o próprio objeto, é preciso que exista também a diferenciação do que é fotografia e o que é realidade: estas não devem se assemelhar tanto para que a fotografia represente algo, seja uma referência, uma alusão ao objeto. Em outras palavras, quando se trata da fotografia, tomamo-la como o objeto real, mas sabemos que não o é.

Quando a fotografia assume o papel de representação, podemos pensá-la como uma interessante ferramenta de expressão. $O$ ato fotográfico seria, então, a expressão visual de um autor, com significados ocultos até para ele mesmo, que se torna sua cúmplice e inevitavelmente fala dele para o mundo, para quem olha suas fotografias (SANTAELLA, 1998).

A imaginação ali impressa pelo fotógrafo permite que este dialogue com sua obra e com o mundo, reconstruindo e reconstituindo a trama de acontecimentos da sua vida e, assim, permite que, ao expressar tais vivências, possa ressignificá-las, repensá-las e elaborar seus conteúdos pessoais. Certamente que nem sempre o diálogo do autor com sua obra se dá espontaneamente ou imediatamente após a tomada da fotografia. Cada imagem ganha um sentido diferente a cada retomada, contemplação, revisitação.

\section{A construção do sentido mediada pela fotografia}

Para que a fotografia ganhe o poder de representar o mundo é preciso contemplação, já que a imagem apartada do pensamento torna-se mero decalque do objeto fotografado. Novaes (2005) coloca que a contemplação da imagem faz o espírito se reconciliar com os sentidos (sensoriais) possibilitando a significaçãol de tais imagens.

Como explanam Spink e Medrado (2000), o sentido diz respeito ao modo como cada um interpreta o mundo à sua volta; conceito que em si engendra a flexibilidade em oposição a resultados objetivos que direcionariam, à luz da razão pura, as análises e conclusões de uma pesquisa quantitativa. Mas lidar com o sentido, construindo-o ou interpretando-o, é estar frente a um fenômeno mutável e dinâmico, já que o modo de ver e lidar com o que se passa à nossa volta transforma-se à medida que modificamos o mundo e por ele somos modificados.

Contudo, a contemplação não é o único elemento que deve estar presente para que uma fotografia ganhe sentido. A construção do sentido envolve uma quebra da rotina ou do modo ordinário de se relacionar com o mundo, ou seja, algo nos força a buscar novas explicações ou modos de agir. Quando ocorre esta ruptura abre-se a possibilidade, dentro de cada momento e contexto, para a busca de 
novos sentidos, já que os antigos não funcionam tão bem quanto antes (SPINK; MEDRADO, 2000).

O catalisador para a ruptura que impulsiona a produção de sentido pode ser um terapeuta, um coordenador de grupo, o professor de fotografia ou um amigo que olha nosso álbum de fotografias, ou seja, um agente externo.

\section{A fotografia nas pesquisas em Psicologia}

No caso das pesquisas em Psicologia, o pesquisador pode funcionar como o agente disparador do processo de significação mediante o uso da fotografia, como podemos perceber no trabalho de Raquel Paternostro (2006), "O uso da fotografia como instrumento no processo de orientação vocacional para adolescentes", em que a fotografia é salientada como um importante procedimento interventivo na orientação vocacional.

Baseando-se nas colocações teóricas de Winnicott e em um caso clínico, esta autora mostra que o ato de fotografar torna-se um facilitador para o adolescente no momento da escolha da profissão. Cabe ressaltar que a escolha da fotografia como procedimento, como relata a autora, é fruto de sua própria experiência com esta técnica que the trouxe a "possibilidade de entrar em contato com aspectos meus até então desconhecidos" (PATERNOSTRO, 2006, p.10). Quanto à metodologia da dissertação, após alguns encontros e testes que investigam a personalidade e os interesses pessoais do adolescente, a pesquisadora dá-Ihe a tarefa de fazer uma fotografia que expresse sua percepção sobre "trabalho". Esta experiência de autoria possibilitou que o adolescente, ao retratar o que a ele era externo, entrasse em contato com a sua forma de perceber a realidade, ressignificando vivências e repensando formas de agir no mundo.

Carmem Justo (2003) utilizou a fotografia para trabalhar as representações sociais de crianças e adolescentes sobre seus bairros, casas, famílias, amigos e si mesmos. Na pesquisa "Os meninos fotógrafos e os educadores: viver na rua e no Projeto Casa" foram distribuídas máquinas fotográficas descartáveis que deveriam ser compartilhadas, cada uma, por dois participantes. A cada um caberiam 12 poses e, depois de reveladas as imagens, o grupo se reuniu e conversou sobre o que cada um havia escolhido registrar. Em seguida foi instruído que cada participante escolhesse quatro das doze fotografias que melhor representassem o que sentiam a respeito de si mesmos. A conversa sobre estas imagens foi realizada sob a forma de entrevistas individuais semi-estruturadas e pôde-se perceber que a tomada de fotografias fez com que os participantes olhassem de uma forma diferenciada, reflexiva, para o ambiente em que vivem e, posteriormente, para si mesmos, percebendo o sentido atribuído a estes elementos no momento da pesquisa. 
Pensando a fotografia como uma linguagem, Altivir Volpe (2007) se propõe a investigar se a fotografia, aliada à narrativa, propicia um espaço de trocas e comunicação entre pesquisador e entrevistado. Para tanto, são realizadas entrevistas individuais e em grupo. Nas entrevistas individuais o pesquisador pede que sejam selecionadas, dentre o acervo pessoal do entrevistado, quatro fotografias que representassem algo se si e de sua história. Após ouvir a narrativa sobre as imagens pede-lhe que escolha uma fotografia e crie uma história. O pesquisador faz interpretações pontuais destas entrevistas e histórias, embasando-se no método psicanalítico de Winnicott.

Em seguida, é realizada uma reunião com os seis participantes da pesquisa, o pesquisador e duas observadoras, estudantes de Psicologia, que anotaram as falas e construções deste encontro. $O$ objetivo desta reunião foi, em grupo, percorrer os mesmos caminhos das entrevistas individuais, ou seja, a observação e narrativas sobre fotografias e a construção de uma história. Cada participante retoma suas fotografias e se apresenta para o grupo criando, posteriormente, uma história embasada em uma de suas fotografias. Ao final o grupo escolhe um título para o conjunto de histórias e conversa sobre a experiência de participar da pesquisa.

Volpe (2007) pensa a fotografia como uma linguagem em cujo diálogo participam tanto o autor quanto o observador. O autor é aquele que dá visibilidade à cena, que escolhe o recorte determinado a capturar o mundo em imagens e que nos faz perguntar se aquelas pessoas estão na cena propositalmente ou não. O observador, dispondo do seu olhar, é o que faz da fotografia algo além do registro documental. Sob a forma de linguagem a fotografia se apresenta de modo a impulsionar o "ver" e o significar do mundo.

A fotografia foi um "lugar de encontro" (VOLPE, 2007, p. 175) de narrativas e memórias. Neste lugar de encontros a fotografia foi 0 desvelador de sentidos à medida que os participantes inventavam histórias e reinventavam suas histórias pessoais ao narrá-las para o pesquisador e para o grupo.

A experiência de narrativa aliada à retomada de fotografia também foi explorada por Joana Sanches Justo (2008) em sua pesquisa "Olhares que contam histórias: a fotografia como memórias e narrativas da família". Foram contatadas duas famílias e participaram da pesquisa três membros de cada uma, totalizando seis entrevistados. Semelhante à pesquisa de Volpe (2007), foi pedido que os participantes separassem 10 fotografias que representassem momentos importantes vividos em família. Após esta seleção inicial, foram realizadas entrevistas no intuito de investigar a relação de cada participante com seus acervos fotográficos e rastrear os sentidos pessoais a respeito das fotografias de família.

Durante as entrevistas alguns posicionamentos na relação com a fotografia se destacaram: os mais jovens pareciam não ter muito o 
que dizer além do que estava explícito na imagem; os mais velhos se apropriavam da narrativa sobre os acontecimentos registrados nas fotografias e transpareciam a sabedoria de quem já viveu muito e sabe do passado e das lembranças que relata e, finalmente, os participantes que não haviam selecionado previamente as fotografias e que, portanto, não revisitaram seu acervo e suas memórias antes da entrevista, se surpreenderam diante das lembranças que estavam há muito tempo esquecidas.

O contato com a fotografia, portanto, disparou diferentes discursos e construiu sentidos singulares. Os mais jovens relatavam uma construção de família ideal, descrições literais das imagens apresentadas, como se a juventude não houvesse acumulado história suficiente para que pudesse ser feito um resgate ou uma ressignificação. Os mais velhos trouxeram uma história mais elaborada, apreendida aos poucos tal qual o vinho que com o tempo vai sendo curado e encorpado. Vivências de nascimentos e mortes, conquistas, recaídas e amizades (JUSTO, 2008).

Nessa pesquisa, o contato dos participantes com as próprias lembranças foi um reencontro pessoal como se a fotografia lhes mostrasse um espelho que, ao mostrar o passado, Ihes permitia perceber o presente, o quanto as coisas mudaram, os filhos que nasceram, os amigos que morreram, as árvores hoje já crescidas e a casa pronta, enfim, algumas experiências que ficaram esquecidas juntos com os álbuns de fotografias.

O reencontro com as fotografias pessoais, tal como na pesquisa de Volpe (2007), fez com que houvesse a oportunidade de reviver experiências, recriar sentidos e preencher lacunas da memória, uma vez que a narrativa das recordações nada mais é do que criar novas histórias e sentidos para as lacunas da memória. É o ato de narrar que possibilita a construção de sentido para as fotografias e, conseguintemente, para as vivências que elas evocam.

A narrativa é um elemento intrínseco ao contato com as fotografias, principalmente quando se trata de um acervo pessoal. Mostrar nossas fotografias a quem quer que seja requer uma explicação, um adendo ao que a fotografia, por ser recorte e estática, não pode dizer. É neste lapso, nesta falta de subjetividade própria e autônoma da fotografia pessoal que o pesquisador da Psicologia encontra possibilidades de intervenção.

É o pesquisador quem dará a direção básica da pesquisa, o incentivo à fala, o "empurrão". Foi exatamente o que aconteceu nas pesquisas acima descritas. Ainda, a relação do participante com a fotografia é não apenas iniciada pela pesquisa, mas mantida pelas atividades e entrevistas. O participante é convidado a mergulhar nas suas próprias memórias e representações sobre o que o cerca e envolve.

A fotografia recebe duplamente o papel de dar visibilidade: mostrar o fragmento do mundo que seu autor escolheu para capturar e, por 
outro lado, fazer "ver", resgatar memórias, construir sentidos para uma realidade que outrora era despercebida. Mediado pelo pesquisador o contato com a fotografia impele os participantes a perceber, refletir e significar.

\section{Conclusão}

A pesquisa qualitativa utilizada em investigações na área de Psicologia permite o estudo da subjetividade, possibilitando a busca de diferentes formas de produção do conhecimento sobre si e sobre o mundo.

O psicólogo, estudando e desvendando as significações levantadas no decorrer da pesquisa, entra em contato com a realidade que estuda, constrói instrumentos, observa, instiga e, através dos procedimentos que utiliza, transforma tal realidade. O que se pode esperar, então, da pesquisa qualitativa em Psicologia é, mais do que comprovar teorias, apontar os sentidos que a realidade estudada faz emergir. Para compreender e interpretar os dados coletados em entrevistas semi-estruturadas, os pesquisadores conferem à fala e à linguagem um lugar especial, capaz de abrir caminhos para que as significações possam emergir.

A fotografia, por sua vez, é um enquadramento da realidade e, além disso, a captura de um momento único e fugaz, o que faz dela um fragmento do passado. Esta questão traz a imagem fotográfica como um elemento complexo, capaz de desencadear processos comunicacionais e subjetivos.

O encontro da fotografia com a narrativa incita o contato com questões, o dialogar, o colocar-se frente a si mesmo e reconstruir-se, através da fotografia que, tal como a imagem nos sonhos, abre caminho para a expressão do sujeito, de sua subjetividade e de seu modo de ver e compreender suas vivências. É um exercício cognitivo de criar e recriar mundos, do autor e também do leitor, constituindo um processo comunicativo.

Uma fotografia, ainda que não seja uma imagem pessoal ou autoral, pode levar o observador a relacionar o que vê ali representado e seu mundo particular. Diante da imagem o pensamento se estende e acaba por criar especulações sobre as formas e cenas fotografadas: um discurso dinâmico em que a fotografia pode até mesmo ser transformada em outra realidade muito distante daquela que o autor tentou captar. Surge um antes e um depois daquela imagem estática, daquele fragmento do real, incompleto, que nos incita a completá-lo com palavras. Por isso, produzir imagens é também criar histórias pessoais e culturais, mediante as quais o homem pode narrar, comunicar e compreender sua própria existência.

Quando utilizada, a fotografia, por seu caráter expressivo e plástico, possibilita colocar imagens onde ainda não há palavras, dar forma ao indefinido e, depois, olhar para este conteúdo e significá-lo. Para 
aquele que a observa, uma fotografia é tanto contemplação quanto espelho daquele que contempla. Observar uma fotografia é, muito além de um instrumento lúdico, um ato criativo capaz até de criar novos valores. É mais do que decodificar uma mensagem objetiva, mas sim marcar a imagem, revê-la, refazê-la e, assim, construir através do olhar.

A fotografia vem sido utilizada nas pesquisas em Psicologia como um facilitador para a produção de sentido. Contudo, ainda são poucas as pesquisas feitas por psicólogos em que a fotografia ocupe um lugar de destaque como instrumento eliciador da subjetividade.

Apesar da maior abertura a novas formas de linguagem na metodologia da pesquisa em Psicologia, a fotografia é tomada como um instrumento de suporte, como documento e às vezes como uma desculpa, um engodo para que os participantes se convençam a falar. Certamente não estamos desmerecendo as pesquisas que se utilizam da fotografia de outras formas, pelo contrário, o objetivo da presente discussão é abrir caminhos, explorar possibilidades e não se deter diante de qualquer alternativa, tal como a que poderíamos propor sob a seguinte indagação: será que ao invés de suporte a fotografia poderia ser tomada como ação?

Reiterando, a fotografia dispara conteúdos subjetivos quando o participante seleciona algumas de suas imagens guardadas e narra suas experiências, mas, o potencial desta técnica surge quando o participante é incentivado a criar suas próprias e inéditas imagens, quando o instrumento de apoio se torna ato fotográfico.

Existe uma diferença fundamental entre trazer fotografias prontas e criar suas próprias. O processo de criação envolve o sujeito em um processo subjetivo de busca e descoberta de si mesmo, de sua identidade e das suas relações com o mundo. Muda-se o narrador da história que outrora era contada por alguém de fora, muitas vezes anônimo ou esquecido, pois ao observarmos uma fotografia nos preocupamos mais em relembrar o fato do que com o autor que capturou tal momento. Por outro lado, quando o autor é o próprio sujeito, a narrativa sobre tais imagens se amplia, surge o antes e o depois da fotografia, os motivos que levaram o autor a escolher tal enquadramento, tal cena, o momento exato do clique.

O autor, ao expressar-se através da fotografia, precisa fazer algumas opções quanto ao recorte que dará à cena, ao enquadramento, foco etc., pois mesmo que se queira captar tudo que o olho humano enxerga, o aparelho fotográfico inevitavelmente obriga uma seleção. É justamente neste momento, onde é apenas o autor quem escolherá o recorte da cena, que este implica a sua subjetividade na obra que está a produzir e transfere a ela sua singularidade.

O que se materializa na fotografia autoral é o reflexo do autor, seu espelho que ao devolver-lhe seu olhar no momento da rememoração diante da fotografia, faz com que a história contada seja a sua 
própria versão dos acontecimentos. Isso traz uma maior apropriação do que é narrado, das construções subjetivas que vão sendo provocadas pela pesquisa e, portanto, da veracidade e validade dos dados obtidos.

\section{Referências Bibliográficas}

BERLO, D. K. O processo da comunicação: introdução à teoria e prática. Rio de Janeiro: Aliança, 1963.

BLIKSTEIN. I. Kaspar Hauser ou a fabricação da realidade. São Paulo: Cultrix, 1983.

JUSTO, C. S.S. Os meninos fotógrafos e os educadores: viver na rua e no Projeto Casa. São Paulo: Ed. UNESP, 2003.

JUSTO, J. S. Olhares que contam histórias: a fotografia como memórias e narrativas da família. 2008.139f. Dissertação (Mestrado em Psicologia e Sociedade) - Faculdade de Psicologia, Universidade Estadual Paulista (UNESP), Assis.

NEIVA-SILVA, L; KOLLER, S. H. O uso da fotografia na pesquisa em Psicologia. Estudos de Psicologia, Porto Alegre, v.7, n.2, p. 237250, jul-dez 2002.

NOVAES, A. A imagem e o espetáculo. In: Muito além do espetáculo. São Paulo: Editora Senac São Paulo, 2005, p.09-15. PARREIRA, S. M. C. P. Experimentar-te: As oficinas de recursos expressivos em uma casa abrigo. 2005.174f. Dissertação (Mestrado em Psicologia e Sociedade) - Faculdade de Psicologia, Universidade Estadual Paulista (UNESP), Assis.

PATERNOSTRO, R.C.C. O uso da fotografia como instrumento no processo de orientação vocacional para adolescentes. São Paulo, 2006. 119f. Dissertação (Mestrado em Psicologia Clínica) Faculdade de Psicologia, Pontifícia Universidade Católica, São Paulo. PINTO, E. B. A pesquisa qualitativa em Psicologia Clínica. Revista de Psicologia da USP, São Paulo, v. 15, n. 1, p. 71-82, jul-dez 2004. REY, F. L. G. La investigación cualitativa em Psicologia: Rumbos y desafios. São Paulo: EDUC, 2001.

SANTAELLA, L. Os três paradigmas da imagem. In: SAMAIN, E. O fotográfico. São Paulo: Hucitec, 1998, p. 167-178.

SPINK, M. J; MEDRADO, B. Produção de sentidos no cotidiano: uma abordagem teórico-metodológica para a análise das práticas discursivas. In: _._. Práticas discursivas e produção de sentidos no cotídiano - aproximações teóricas e metodológicas. São Paulo: Cortez, 2000, p. 41-61.

VOLPE, A. J. Fotografia, narrativa e grupo: lugares onde pôr o que vivemos. 2007. 197f. Tese (Doutorado em Psicologia Social) Instituto de Psicologia, Universidade de São Paulo, São Paulo. Disponível em: http://www.teses.usp.br/teses/disponiveis/47/47134/tde-05052008171045/ Acesso em: 10 fev. 2009. 
WOLFF, F. Por trás do espetáculo: o poder das imagens. In: NOVAES, A. (org). Muito além do espetáculo. São Paulo: Editora Senac São Paulo, 2005, p.16-45.

\section{Endereço para correspondência}

J oana Sanches J usto

UNESP, Av. Dom Antonio, 2100, CEP 19806-900, Assis-SP, Brasil

Endereço eletrônico: joana_sj@yahoo.com.br

Mário Sérgio Vasconcelos

UNESP, Av. Dom Antonio, 2100, CEP 19806-900, Assis-SP, Brasil

Endereço eletrônico: vascon@assis.unesp.br

Recebido em: 04/06/2009

Aceito para publicação em: 13/10/2009

Acompanhamento do processo editorial: Ana Maria Lopez Calvo Feijoo

\section{Notas}

* Mestre em Psicologia e Sociedade pela Universidade Estadual Paulista (UNESP), Assis, Especialista em Práxis e Discurso fotográfico pela Universidade Estadual de Londrina (UEL), Londrina.

**Pós-doutor em Processos Cognitivos pela Universidade de Barcelona, Doutor em Psicologia Escolar e do Desenvolvimento Humano pela Universidade de São Paulo (USP), São Paulo, Mestre em Psicologia Social pela Pontifícia Universidade Católica (PUC), São Paulo. 